\title{
Characterisation of Mesorhizobium huakuii cyclic $\beta$-glucan
}

\author{
Adam Choma and Iwona Komaniecka
}

Department of General Microbiology, Maria Curie-Sklodowska University, Lublin, Poland

Received: 07 October, 2003; revised: 25 November, 2003; accepted: 09 December, 2003

Key words: Mesorhizobium huakuii, cyclic $\beta$-glucan, OPG, MALDI-TOF, NMR, osmoregulation

\begin{abstract}
Periplasmic and extracellular glucans of Mesorhizobium huakuii were isolated and characterized by compositional and MALDI-TOF analyses, as well as ${ }^{1} \mathrm{H}$ and ${ }^{13} \mathrm{C}$ NMR spectroscopy. It was shown that $M$. huakuii produces a cyclic $\beta$-glucan composed entirely of nonbranched glucose chains and unmodified by nonsugar substituents. The degree of polymerisation of the cyclic oligosaccharides was estimated to be in the range from 17 to 28 . The most abundant glucan molecules contained 22 glucose residues. Glucose residues within the glucan were connected by $\beta-(1,2)$ glycosidic linkages. The cyclic glucan produced by $M$. huakuii is quite similar to the periplasmic $\beta-(1,2)$ glucans synthesized by Agrobacterium and Sinorhizobium genera. The synthesis of $\beta$-glucan in M. huakuii is osmoregulated and this glucan could function as an osmoprotectant in free living cells.
\end{abstract}

A specific compartment between the cytosol and the outer membrane, named periplasmic space, exists in Gram-negative bacteria. This compartment tends to remain isoosmotic with the cytosol over a range of extracellular conditions (Stock et al., 1977), a function that is accomplished by specific oligosaccharides. In $E$. coli, those oligosaccharides were named MDO (membrane-derived oligosaccharides) (Schulman \& Kennedy, 1979). MDO are linear molecules composed of 6 to 8 glucose residues linked by $\beta-(1,2)$ and branched by $\beta$-(1,6)-glycosidic bonds and substituted with phosphoglycerol, phosphoethanolamine and succinyl residues (Schneider et al., 1979).

Osmoregulated periplasmic glucans (OPG) in other Gram-negative bacteria play the same role as MDO molecules. $\beta$ - $(1,2)$ glucans or $\beta$-(1,3); $(1,6)$ glucans are commonly found within bacteria of the order "Rhizobiales" (i.e. Rhizobium, Agrobacterium, Sinorhizobium, Brucella, Bradyrhizobium and Azorhizobium genera) (York et al., 1980; Batley et al., 1987; Hisamatsu et al., 1987; Miller et al., 1987; Briones et al., 1987; Breedveld \& Miller, 1998; Rolin et al., 1992; Komaniecka \& Choma,

\footnotetext{
${ }^{\circledR}$ Corresponding author: Adam Choma, Department of General Microbiology, Maria Curie-Sklodowska University, Akademicka 19, 20-033 Lublin, Poland; tel.: (48 81) 537 5981; fax: (48 81) 537 5959; e-mail: achoma@biotop.umcs.lublin.pl
}

Abbreviations: LMW-EPS, low molecular mass exopolysaccharide; MDO, membrane-derived oligosaccharides; OPG, osmoregulated periplasmic glucans. 
2003). These bacteria secrete a fraction of glucans into the medium but, nevertheless, the main pool is found within the periplasmic space (Abe et al., 1982). $\beta$-Glucan production is affected by external osmolarity in most bacteria examined (Miller et al., 1986; Dylan et $a l .$, 1990). The suppression of biosynthesis of the periplasmic OPG and MDO during growth in high-osmolarity media indicates a role of $\beta$-glucans in adaptation of the bacteria to low osmolarity conditions (Miller et al., 1986). Export of OPG to the extracellular environment has been observed in many members of the order Rhizobiales. Extracellular glucans may act as an important factor in plant-microbe interactions (Bhagwat et al., 1999; Breedweld \& Miller, 1994). These cyclic $\beta$-(1,2)-glucans are implicated in the formation of nitrogen-fixing nodules on host plants (Breedweld \& Miller, 1994; Batley et al., 1987; Hisamatsu et al., 1987). The level of OPG export varies greatly among different species and strains, and depends on growth stage and culture conditions.

The best known OPGs from Sinorhizobium meliloti and Agrobacterium tumefaciens are composed of 17 to $25 \beta$-(1,2)-linked D-glucose residues that may be substituted with phosphoglycerol, succinate or methylmalonate groups. In $S$. meliloti cells sn-1-phosphoglycerol, linked to position 6 of glucose, is the predominant substituent of cyclic glucans. The sn-1-phosphoglycerol is derived from the head group of cytoplasmic membrane phosphatidylglycerol. A specific transferase acts during the transport of neutral glucans across the outer membrane.

Cyclic $\beta$-(1,3);(1,6) glucan produced by Bradyrhizobium japonicum or Azorhizobium is composed of 11 to 13 glucosyl residues (Miller et al., 1990; Rolin et al., 1992; Komaniecka \& Choma, 2003). A fraction of the molecules in bradyrhizobial cells is substituted with phosphocholine. The Bradyrhizobium cyclic $\beta$-glucans appear to be functionally equivalent to the cyclic $\beta$ - $(1,2)$ glucans during hypoosmotic adaptation (Miller \& Gore, 1992).
The knowledge about mesorhizobial glucan structure and its biosynthesis is limited to a few publications. Slow growing strain of Rhizobium loti synthesises an oligosaccharide resembling the glucan from $B$. japonicum (Estrella et al., 2000). A fast growing strain of $R$. loti isolated from Lotus tenuis was found to synthesise $\beta$ - $(1,2)$ glucan typical for Rhizobium genera (Lepek et al., 1990). Rhizobium huakuii My6 produces and excretes oligosaccharides that are structurally identical to those of the fast growing $R$. loti (Hisamatsu et $a l$. , 1997). However, the results described in that paper, were based only on a comparison of the chromatographic profile of isolated My6 glucan to the chromatographic profiles of glucan preparations of known structure.

In this report we present the results of structural studies on the periplasmic and extracellular oligosaccharides from Mesorhizobium huakuii. The effect of osmotic strength of the growth medium on glucan biosynthesis is described. Our investigation of the $\beta$-glucan synthesised by $M$. huakuii IFO $12543^{\mathrm{T}}$ completes the previous work of Hisamatsu et al. (1997) on mesorhizobial secreted polysaccharides. We show that $M$. huakuii accumulates $\beta$-glucan within the periplasm and exports some of it to the environment without biochemical modification.

\section{MATERIALS AND METHODS}

Mesorhizobium huakuii IFO $15243^{\mathrm{T}}$ is the type strain from the Culture Collection of the Institute for Fermentation (Osaka, Japan). This strain was isolated from Astragalus sinicus in China and has the original denotation CCBAU 2603 (Nuswantara et al., 1997).

Bacteria were grown in liquid mannitol-yeast extract medium 79CA (Vincent, 1970) and were aerated by vigorous shaking. Cells and culture supernatant were separated by centrifugation. The cell pellet was washed twice with saline and once with distilled water. Cell-associated glucans were liberated 
from the periplasmic space by a modified Bligh and Dyer extraction procedure (Miller et al., 1988). Aqueous methanol fractions were concentrated by rotary evaporation and chromatographed on a Sephadex G50 column $(1.6 \times 80 \mathrm{~cm})$. The column was washed with $0.15 \mathrm{M}$ ammonium acetate ( $\mathrm{pH} 7.0$ ) containing $7 \%(\mathrm{v} / \mathrm{v})$ propanol. The flow rate was 15 $\mathrm{ml} \mathrm{h}^{-1}$ (Miller et al., 1990). Fractions (1 ml) were collected and assayed for total carbohydrate by the phenol-sulfuric acid method (Dubois et al., 1956). The fractions containing oligosaccharides were pooled, concentrated and desalted on a Bio-Gel P2 column $(1.6 \times$ $60 \mathrm{~cm}$ ) (Bio-Rad) with 7\% propanol in water as the eluent. The desalted samples were then separated on a DEAE-cellulose column $(1 \times$ $27 \mathrm{~cm}$ ) (DE 23; Whatman). After application of the sample, the column was washed with 40 $\mathrm{ml}$ of $10 \mathrm{mM}$ Tris/HCl (pH 8.4). Next, $100 \mathrm{ml}$ gradient was applied, starting with $0 \mathrm{mM} \mathrm{KCl}$ and ending with $200 \mathrm{mM} \mathrm{KCl}$ in the same Tris/HCl buffer (Miller et al, 1988; 1990). The flow rate was $24 \mathrm{ml} \mathrm{h}^{-1}$. Fractions ( $2 \mathrm{ml}$ ) were assayed for total carbohydrate by the phenol-sulfuric acid method. Carbohydrate containing fractions were collected and dialysed against distilled water.

Culture supernatant was condensed fourfold by rotary evaporation. The high-molecular-mass polysaccharides (EPS) were precipitated by adding 3 vol. of ethanol, as described previously (Bhagwat et al., 1999; Lee et al., 2001), whereas low-molecular-mass oligosaccharides remained in the supernatant ( $75 \%$ alcohol). The material from the supernatant was concentrated and separated using BioGel P2 column chromatography $(1.6 \times 57 \mathrm{~cm})$ with $7 \%$ propanol in water $(\mathrm{v} / \mathrm{v})$ as the eluent, to remove medium salts. The flow rate was 15 $\mathrm{ml} \mathrm{h}^{-1}$. Fractions $(3 \mathrm{ml}$ ) were collected and sugar compounds were determined. The glucan containing fraction was further analysed in the same way as cell-associated glucan.

In order to examine the effects of growth in a high-osmotic-strength medium on glucan synthesis, $0.25 \mathrm{M} \mathrm{NaCl}$, $0.5 \mathrm{M}$ mannitol or 0.5 $\mathrm{M}$ glucose was introduced into the 79CA medium. Bacterial cells from 6-day-old cultures were centrifuged, washed twice with saline and once with distilled water. The amount of total cellular protein was determined according to Lowry (Lowry et al., 1951) using bovine serum albumin as a standard. To determine the amount of periplasmic glucan cell pellets were subjected to the procedure described by Breedveld and co-workers (Breedveld et al., 1993). Finally, all 50\% alcohol extracts that contained periplasmic glucans were quantified for carbohydrates by the phenol-sulfuric acid procedure.

For compositional analysis, glucan samples were hydrolysed with $2 \mathrm{M} \mathrm{TFA}\left(100^{\circ} \mathrm{C}, 4 \mathrm{~h}\right)$ and the liberated sugars were converted into alditol acetates.

Methylation analysis was done according to a modified Hakomori procedure, as described by York and co-workers (York et al., 1986). Part of the methylated sample was hydrolysed with $2 \mathrm{M}$ TFA, reduced with $\mathrm{NaBD}_{4}$, peracetylated and then partially methylated alditol acetates were analysed by GC-MS. The remaining part of the material was analysed by MALDI-TOF (matrix-assisted laser desorption ionisation - time of flight mass spectrometry).

Alditol acetates and partially methylated alditol acetates were analysed using a Hewlett-Packard gas chromatograph (model HP 5890A) coupled to a mass selective detector (MSD HP 5971). The gas chromatograph was equipped with a capillary column (HP-5MS, $30 \mathrm{~m} \times 0.25 \mathrm{~mm}$ ) and helium was the carrier gas (flow rate was $0.7 \mathrm{ml} \mathrm{min}^{-1}$ ). For the alditol acetate analysis the temperature program was as follows: $150^{\circ} \mathrm{C}$ for $5 \mathrm{~min}$, then raised to $310^{\circ} \mathrm{C}\left(5^{\circ} \mathrm{C} \mathrm{min}{ }^{-1}\right)$ and the final temp. was $310^{\circ} \mathrm{C}$ for $20 \mathrm{~min}$. For analysis of partially methylated alditol acetates the temperature program was: $70^{\circ} \mathrm{C}$ for $2 \mathrm{~min}$, then raised to $150^{\circ} \mathrm{C}\left(50^{\circ} \mathrm{C} \mathrm{min}^{-1}\right)$ followed by $3^{\circ} \mathrm{C}$ $\min ^{-1}$ to the final temperature of $310^{\circ} \mathrm{C}$. 
MALDI-TOF analysis was performed on a Voyager -Elite (PE Biosystems) instrument in positive-ion mode. The methylated samples of glucan were dissolved in chloroform/methanol $(2 / 1: \mathrm{v} / \mathrm{v})$, then mixed with a matrix of gentisic acid solution in acetonitrile (50\%, $\mathrm{w} / \mathrm{v})$. The solvents were allowed to dry. Samples were desorbed with a nitrogen laser, and a $20 \mathrm{kV}$ extraction voltage was used. The spectra obtained are the average of 256 (periplasmic glucan sample) or 122 (extracellular glucan preparation) scans.

1-D and 2-D ${ }^{1} \mathrm{H}$ NMR, as well as ${ }^{13} \mathrm{C}$ NMR experiments were carried out on a Bruker 300 instrument at $313^{\circ} \mathrm{K}$ using standard software. Samples were dissolved in $\mathrm{D}_{2} \mathrm{O}$. Acetone was the internal standard $\left(\delta_{\mathrm{H}}=2.225\right.$ p.p.m., $\delta_{\mathrm{C}}=31.45$ p.p.m.).

\section{RESULTS AND DISCUSSION}

The purified oligosaccharides from the periplasm of $M$. huakuii cells and from culture supernatant were separated by ion-exchange chromatography using a DEAE-cellulose column. Fractions rich in glucose were found to elute prior to the applied $\mathrm{KCl}$ gradient. This is indicative of a neutral polymer (Fig. 1). In contrast to mesorhizobial periplasmic oligosaccharides, glucan molecules isolated from Agrobacterium or Sinorhizobium were found to be partly substituted by phosphoglycerol, phosphoethanolamine or succinate residues and, having a highly anionic character, were retarded by anionic chromatographic columns (Breedweld \& Miller, 1994; Miller et al., 1988). In the extracellular glucan fraction, small quantities of galactose and ribose accompanying the main component, glucose, were identified. These contaminants could derive from LMW-EPS, as was described in R. huakuii My6 (Hisamatsu et al., 1997).

The range of molecular mass of the cell-associated glucan preparations was determined by positive-ion MALDI-TOF spectrum of the methylated sample (Fig. 2). This analysis re-
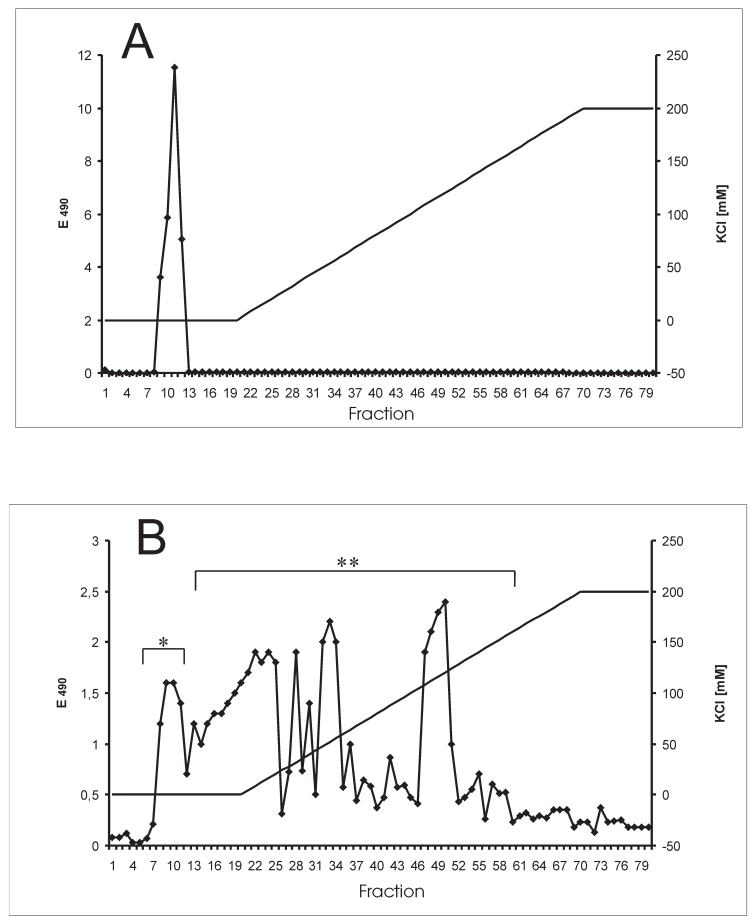

Figure 1. DEAE-cellulose anion-exchange column chromatography profiles of cell-associated (A) and extracellular (B) cyclic $\beta$-(1,2)-glucans from M. huakuii IFO $15243^{\text {T }}$.

Potassium chloride gradient is indicated by solid line. ${ }^{*}$ fraction rich in $\beta$-glucan; ${ }^{* *}$ fraction representing LMW-EPS.

vealed the presence of several sodium-cationized molecular ions $[\mathrm{M}+\mathrm{Na}]^{+}$. The pseudomolecular ion species had masses identical to those expected for a cyclic form of glucan composed of 17 to 28 glucose residues. Among them, the ion at $\mathrm{m} / z 4517$ was the most intense. This signal represented the main glucan species containing 22 glucose residues within the ring. The theoretically calculated mass for native glucan is $3567.102 \mathrm{Da}$ and for its methylated form it is $4492.884 \mathrm{Da}$. The pattern of molecular masses obtained for the extracellular glucan fraction was identical to that obtained for the periplasmic glucan sample. Similar ranges of the ring size were observed in the case of Rhizobium, Sinorhizobium and Agrobacterium cyclic glucans. It is worth noticing that the major glucan species, containing 22 glucose residues, is close to the range typical for glucans dominating in Rhizobium and Agrobacterium (19-20 glucose 
residues per ring) (York et al., 1980; Batley et al., 1987; Hisamatsu et al., 1987).

GC-MS analysis of permethylated alditol acetates derived from both periplasmic and extracellular glucan preparations indicated the presence of only 1,2-linked glucose residues (not shown). In GC analysis neither peak cluster of $\mathrm{C} 1$ resonance at 102.7 p.p.m. (Fig. 4). The presence of signals with a chemical shift above 102 p.p.m. indicates $\beta$ configuration of glucose (Usui et al., 1973). There are no signals at 92 to 96 p.p.m. characteristic for the $\mathrm{C} 1$ resonances of reducing glucose residues. These results confirm the previous ob-

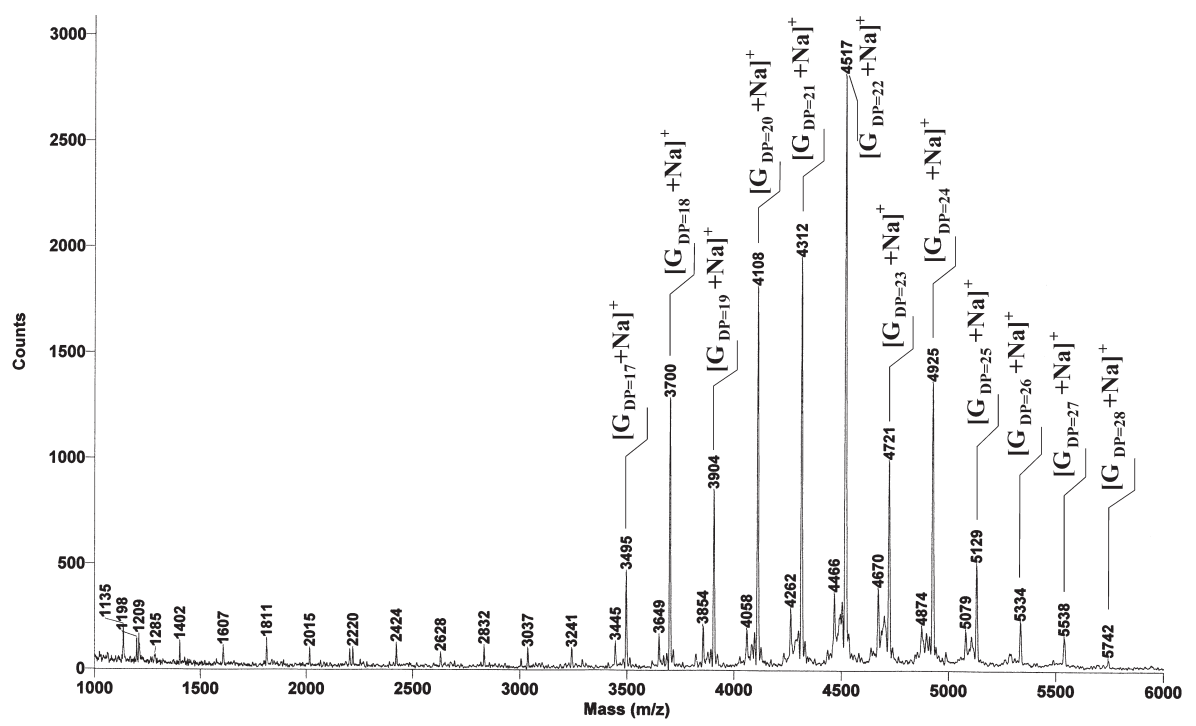

Figure 2. Positive-ion MALDI-TOF mass spectra of methylated glucan sample from M. huakuii IFO $15243^{\mathrm{T}}$.

The $m / z$ values are reported as the nominal mass of the pseudomolecular ion $[\mathrm{M}+\mathrm{Na}]^{+}$. DP, degree of polymerisation.

peaks from fully methylated nor from branched glucose residues were detected. Those results indicate that the periplasmic and extracellular glucans are not branched and that those molecules are cyclic.

In the anomeric region of the ${ }^{1} \mathrm{H}$ NMR spectrum, overlaping dublets at 4.9 p.p.m. were found. The shift values and their coupling constants $\left(\mathrm{J}_{1,2}\right.$ about $\left.8 \mathrm{~Hz}\right)$ are characteristic for $\beta$-configuration of all glucose residues.

Signals between 3.55 p.p.m. and 3.60 p.p.m. correspond to the $\mathrm{H} 2$ protons involved in $\beta$ - $(1,2)$ linkages. Chemical shifts attributed to other protons in the glucan molecule are listed in Table 1. All cross-peaks are indicated on the COSY spectrum (Fig. 3A). On the TOCSY spectrum (Fig. 3B), the glucose spin system starting from the anomeric proton is traced using a solid line. ${ }^{13} \mathrm{C}$ NMR analysis of the periplasmic glucan sample revealed a servation that the glucan molecules are cyclic and all glucose residues are $\beta$-linked. Resonances below 60 p.p.m. were not observed, indicating the absence of nonsugar substituents, e.g. phosphoglycerol or acetyl residues. The resonances at $82-83$ p.p.m. were assigned to $\mathrm{C} 2$ implicated in $\beta$ - $(1,2)$ glycosidic linkages. The absence of a signal at 73 to 74 p.p.m. indicates that all $\mathrm{C} 2$ carbons are involved in glycosidic bonds (Dell, 1983). The multiple resonances of $\mathrm{C} 1$ and $\mathrm{C} 2$ signals derive from cyclic glucan molecules of a wide size range (17 to 28 residues) and are due to the slightly different angles between the adjacent glucosyl residues. All assignments in ${ }^{13} \mathrm{C}$ NMR (Table 1, Fig. 4) were confirmed by a ${ }^{13} \mathrm{C}$-decoupled, ${ }^{1} \mathrm{H}$-detected $\mathrm{HSQC}$ analysis (spectrum not shown).

The above conclusion was confirmed by NOESY experiment. The NOESY spectrum 


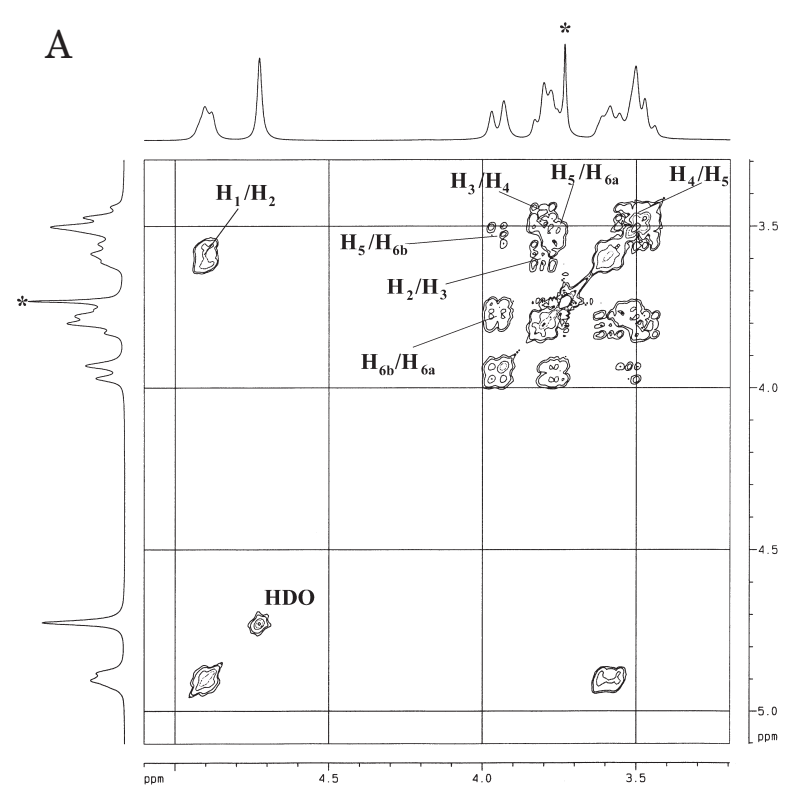

B
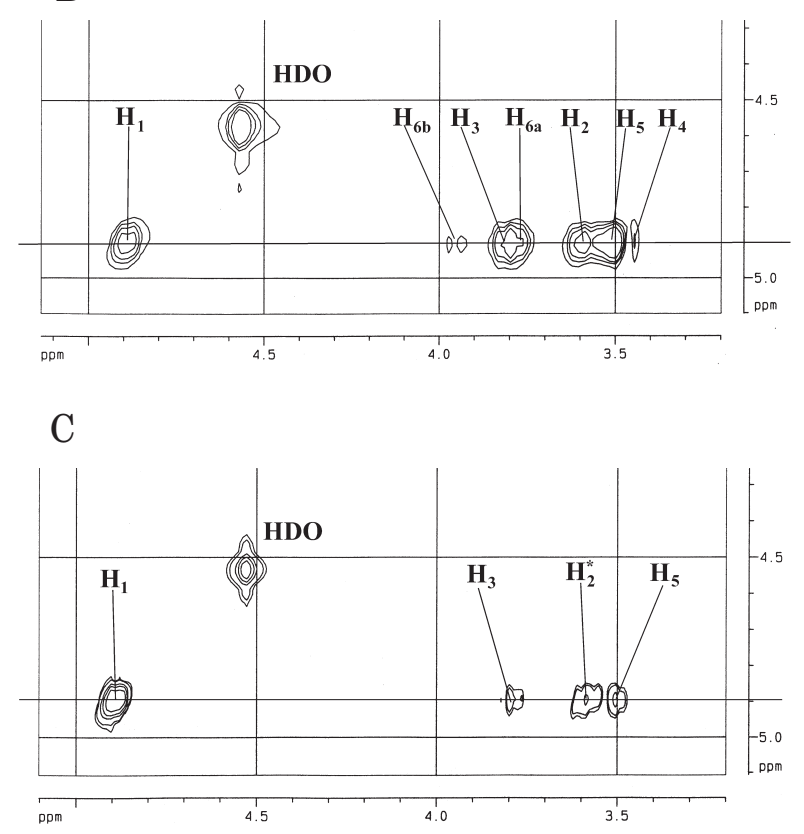

Figure 3. A. DQF-COSY spectrum of M. huakuii glucan (*signal is attributed to Tris contamination). B. Partial TOCSY spectrum of the glucan from $M$. huakuii. The $\mathrm{H}_{1}$ proton ring system is marked. C. Part of NOESY spectrum. The interresidue cross peak $\left(\mathrm{H}_{1} / \mathrm{H}_{2}{ }^{*}\right)$ is marked with asterisk.

revealed a strong transglycosidic correlation between H1 (4.89 p.p.m.) and H2 (3.57 p.p.m.) (Fig. 3C). This correlation signal was accompanied by two cross-peaks, which represented intramolecular interaction between
$\mathrm{H} 1$ and $\mathrm{H} 3$, as well as between $\mathrm{H} 1$ and $\mathrm{H} 5$ protons.

The results of ${ }^{1} \mathrm{H}$ and ${ }^{13} \mathrm{C}$ NMR experiments showed that mesorhizobial periplasmic glucan and the glucan exported to the environment represent the same type of oligosaccharides as the glucans from Rhizobium, Sinorhizobium and Agrobacterium species. However, in contrast to most rhizobial glucans, the glucans from $M$. huakuii were found to be unsubstituted.

It is well known that $B$. japonicum, $A$. tumefaciens, as well as most of $S$. meliloti and Rhizobium strains, when grow in a high-osmotic pressure medium, are strongly inhibited in the synthesis and accumulation of periplasmic cyclic glucans (Miller et al., 1986; Dylan et al., 1990). M. huakuii glucan synthesis in the presence of high concentration of different osmolites was examined. The results are listed in Table 2. The quantity of glucans determined in bacteria grown in a medium supplemented with $0.5 \mathrm{M}$ glucose, $0.5 \mathrm{M}$ mannitol or $0.25 \mathrm{M} \mathrm{NaCl}$ was considerably reduced. In the presence of glucose and $\mathrm{NaCl}$ even a two-fold reduction of the quantity of glucans was observed. It is known that the biosynthesis of periplasmic $\beta$-glucans in bacterial cells may increase when the osmolarity of the medium is low, and decrease, even in the presence of osmoprotectants, when the medium osmolarity is raised. This type of osmoregulation is observed in Escherichia coli, Rhodobacter sphaeroides or Erwinia chrysanthemi (Bohin, 2000; Cogez et al., 2001; Talaga et al., 2002). The results of our studies indicate that biosynthesis of cyclic glucans by M. huakuii is osmotic pressure dependent. The observation that the periplasmic pool of $\beta$-glucans is highly dependent on osmolarity of the environment suggests that the mesorhizobial cyclic $\beta$-glucan can function as an osmoprotectant during a free-state growth of this bacterium.

The hypothesis concerning the osmoprotective function of cyclic glucans does not work in the case of bacteroids (Breedveld \& 
Miller, 1998). The osmotic pressure within root nodules is moderately elevated, but the level of $\beta$-glucans synthesised by bacteroids is similar to that in a low osmolarity medium. There are two possible explanations: (i) the regulation of glucan biosynthesis differs from that in the free-living Rhizobium, or (ii) the main function of those oligosaccharides is not

Table 1. ${ }^{1} \mathrm{H}$ and ${ }^{13} \mathrm{C}$ chemical shift assignments for M. huakuii IFO $15243^{\mathrm{T}}$ periplasmic glucan.

\begin{tabular}{llll}
\hline C1 & $102.7^{*}$ & H1 & $4.87-4.89$ \\
C2 & $82.5-83.2$ & H2 & $3.55-3.60$ \\
C3 & 76.2 & H3 & 3.79 \\
C4 & 69.5 & H4 & 3.47 \\
C5 & 77.0 & H5 & 3.50 \\
C6 & 61.5 & H6a & 3.76 \\
& & H6b & 3.92 \\
\hline
\end{tabular}

${ }^{*}$ cluster of at least three signals

osmoprotection. Osmoregulated periplasmic glucans seem to be universal constituents of the envelope of Gram-negative bacteria. Various functions are ascribed in the literature to the particular bacterial $\beta$-glucans. Presum-

Table 2. Glucan biosynthesis in Mesorhizobium huakuii IFO $15243^{\mathrm{T}}$ growing under high-osmotic-strength conditions.

\begin{tabular}{rcc}
\hline Osmolyte & \multicolumn{2}{c}{ Periplasmic glucans } \\
& $\left(\mu \mathrm{g}\right.$ glucose equivalents $\mathrm{mg}^{-1}$ bacterial protein $)$ \\
\hline None (control) & 261.2 & $(\mathrm{~S}=22.4)$ \\
Mannitol $(0.5 \mathrm{M})$ & 190.4 & $(\mathrm{~S}=27.3)$ \\
Glucose $(0.5 \mathrm{M})$ & 122.7 & $(\mathrm{~S}=5.0)$ \\
$\mathrm{NaCl}(0.25 \mathrm{M})$ & 107.9 & $(\mathrm{~S}=36.4)$ \\
\hline
\end{tabular}

Data are the averages from three independent experiments; S, standard deviation.

ably, the biological function of primary importance of these molecules remains to be determined (Talaga et al., 2002)
The similarity of the $\beta$-(1,2) glucan synthesised by $M$. huakuii IFO $15243^{\mathrm{T}}$ and by a fast

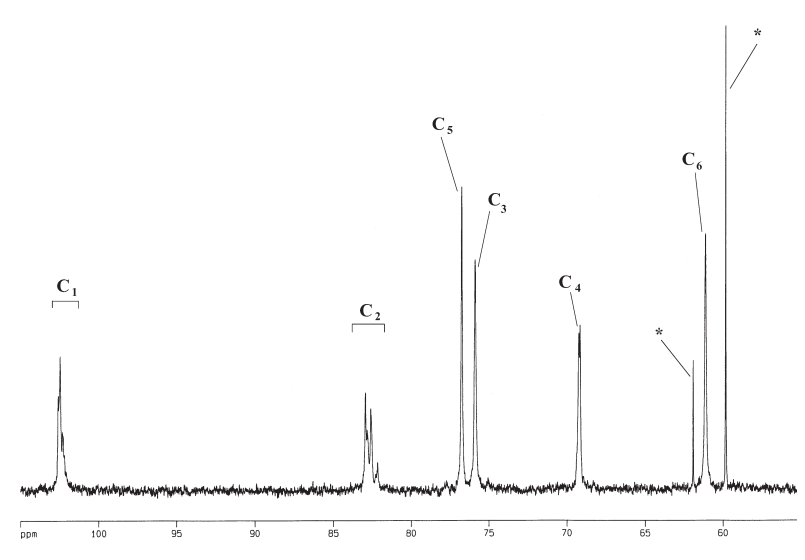

Figure 4. ${ }^{13} \mathrm{C}$ NMR analysis of cyclic $\beta$-(1,2) glucan preparation from $M$. huakuii.

*signals at 60.2 and 62.1 p.p.m. are attributed to Tris contamination of the sample.

growing $R$. loti strain AYAC 1 BII; (Lepek et al., 1990) shows that these bacteria are closely related to the Rhizobium, Sinorhizobium and Agrobacterium cluster. Presumably, all these bacteria possess a very similar enzymatic pathway for $\beta$-glucan synthesis. Interestingly, Estrella and co-workers (Estrella et al., 2000) described the slow growing NZP 2309 strain of Rhizobium loti that produces a $\beta$-(1,3); $(1,6)$ cyclic glucan that is representative for bradyrhizobia. NZP 2309 differs from Bradyrhizobium USDA 110 type strain but is phylogenetically closely related.

\section{R E F E R E N C E S}

Abe M, Amemura A, Higashi S. (1982) Studies on cyclic $\beta$-1,2-glucan obtained from the periplasmic space of Rhizobium trifolii cells. Plant Soil.; 64: 315-24.

Batley M, Redmond JW, Djordjevic SP, Rolfe BG. (1987) Characterisation of glycerophosphorylated cyclic beta-1,2-glucans from a fast growing Rhizobium species. Biochim Biophys Acta.; 901: 119-26. 
Bhagwat AA, Mithöfer A, Pfeffer PhE, Kraus C, Spickers N, Hotchkiss, A, Ebel J, Keister DL. (1999) Further studies of the role of cyclic $\beta$-glucans in symbiosis. An $n d v C$ mutant of Bradyrhizobium japonicum synthesises cyclodecakis- $(1 \rightarrow 3)-\beta$-glucosyl. Plant Physiol.; 119: $1057-64$.

Bohin J-P. (2000) Osmoregulated periplasmic glucans in Proteobacteria. FEMS Microbiol Lett.; 186: 11-9.

Breedveld MW, Miller KJ. (1994) Cyclic $\beta$-glucans of members of the family Rhizobiaceae. Microbiol Rev.; 58: 145-61.

Breedveld MW, Miller KJ. (1998) Cell-surface $\beta$-glucans. In Rhizobiaceae. Spaink HP, Kondorosi A, Hooykaas PJJ, eds, pp 81-96. Kluwer Acad. Publ. Dordrecht, Boston, London.

Breedveld MW, Canter Cremers HJC, Batley M, Posthumus MA, Zevenhuizen LPTM, Wijffelman CA, Zehnder AJB. (1993) Polysaccharide synthesis in relation to nodulation behavior of Rhizobium leguminsarum. J Bacteriol.; 175: 750-7.

Briones G, Iñón de Iannino N, Steinberg M, Ugalde RA. (1997) Periplasmic cyclic 1,2- $\beta$-glucan in Brucella spp. is not osmoregulated. Microbiology.; 143: 1115-24.

Cogez V, Talaga P, Lemoine J, Bohin J-P. (2001) Osmoregulated periplasmic glucans of Erwinia chrysanthemi. J Bacteriol.; 183: 3127-33.

Dell A. (1983) The cyclic structure of beta-D-(1-2)-linked D-glucans secreted by Rhizobia and Agrobacteria. Carbohydr Res.; 117: $185-200$.

Dubois M, Gilles KA, Hamilton IK, Rebers PA, Smith F. (1956) Colorimetric method for determination of sugar and related substances. Anal Chem.; 28: 350-6.

Dylan T, Helinski DR, Ditta GS. (1990) Hypoosmotic adaptation in Rhizobium meliloti requires $\beta$-(1 $\rightarrow 2)$-glucan. $J$ Bacteriol.; 172: $1400-8$.

Estrella MJ, Pfeffer PE, Brouillette JN, Ugalde RA, Iñón de Iannino NI. (2000) Biosynthesis and structure of cell associated glucans in the slow growing Rhizobium loti strain NZP 2309. Symbiosis.; 29: 173-99.

Hisamatsu M, Yamada T, Higashiura T, Ikeda M. (1987) The production of acidic, O-acetylated cyclosophorans (cyclic $(1 \rightarrow 2)-\beta$-glucan) by Agrobacterium and Rhizobium species. Carbohydr Res.; 163: 115-22.

Hisamatsu M, Nomura S, Shutsrirung A, Obata H, Teranishi K, Yamada T, Nuswantara S, Yamashita M, Murooka Y. (1997) Structural characterisation of a new acidic exopolysaccharide and cyclic $(1 \rightarrow 2) \beta$-glucan produced by Rhizobium huakuii forming nodules on Astragalus sinicus. J Ferment Bioengineer.; 83: $315-20$.

Komaniecka I, Choma A. (2003) Isolation and characterisation of cyclic $\beta$-glucan of Azorhizobium caulinodans. FEMS Microbiol Lett.; 227: 263-9.

Lee S, Seo D, Kim H-W, Jung S. (2001) Investigation of inclusion complexation of paclitaxel by cyclohenicosakis- $(1 \rightarrow 2)-(\beta$-D-glucopyranosyl), by cyclic-( $1 \rightarrow 2)-\beta$-D-glucans (cyclosophoraoses), and by cyclomaltoheptaoses ( $\beta$-cyclodextrins). Carbohydr Res.; 334: 119-26.

Lepek V, Navarro de Navarro Y, Ugalde RA. (1990) Synthesis of $\beta(1-2)$ glucan in Rhizobium loti. Arch Microbiol.; 155: 35-41.

Lowry O, Rosebrough AL, Farr RJ, Randall RJ. (1951) Protein measurement with the Folin phenol reagent. $J$ Biol Chem.; 193: 265-75.

Miller KJ, Gore RS, Benesi AJ. (1988) Phosphoglycerol substituents present on the cyclic $\beta$-1,2-glucans of Rhizobium meliloti 1021 are derived from phosphatidylglycerol. J Bacteriol.; 170: 4569-75.

Miller KJ, Gore RS. (1992) Cyclic beta-1,6-1,3-glucans of Bradyrhizobium japonicum: functional analogs of the cyclic cyclic $\beta$-(1,2)-glucans of Rhizobium? Curr Microbiol.; 24: 101-4.

Miller KJ, Gore RS, Johnson R, Benesi AJ, Reinhold VN. (1990) Cell-associated oligosaccharides of Bradyrhizobium spp. J Bacteriol.; 172: $136-42$. 
Miller KJ, Kennedy EP, Reinhold VN. (1986) Osmotic adaptation by gram-negative bacteria: possible role for periplasmic oligosaccharides. Science.; 231: 48-51.

Miller KJ, Reinhold VN, Weissborn AC, Kennedy EP. (1987) Cyclic glucans produced by Agrobacterium tumefaciens are substituted with $s n$-1-phosphoglycerol residues. Biochim Biophys Acta.; 901: 112-8.

Nuswantara S, Fuije M, Sukiman HI, Jamashita M, Jamada T, Murooka Y. (1997) Phylogeny of bacterial symbionts of leguminous tree Acacia mangium. J Ferment Bioeng.; 84: 511-8.

Rolin DB, Pfeffer PE, Osman SF, Szwergold RB, Kappler F, Benesi AJ. (1992) Structural studies of a phosphocholine substituted $\beta$-(1,3);(1,6) macrocyclic glucan from Bradyrhizobium japonicum USDA 110. Biochim Biophys Acta; 1116: 215-25.

Schneider JE, Reinhold V, Rumley MK, Kennedy EP. (1979) Structural studies of the membrane-derived oligosaccharides of Escherichia coli. J Biol Chem.; 254: 10135-8.

Schulman H, Kennedy EP. (1979) Localisation of membrane-derived oligosaccharides in the outer envelope of Escherichia coli and their occurrence in other gram-negative bacteria. J Bacteriol.; 137: 686-8.
Stock JB, Rauch B, Roseman S. (1977) Periplasmic space in Salmonella typhimurium and Escherichia coli. J Biol Chem.; 252: 7850-61.

Talaga P, Cogez V, Wieruszeski JM, Stahl B, Lemoine J, Lippens G, Bohin J-P. (2002) Osmoregulated periplasmic glucans of the free-living photosynthetic bacterium Rhodobacter sphaeroides. Eur J Biochem.; 269: 2464-72.

Usui T, Yamaoka N, Mastuda K, Tuzimura K, Sugiyama H, Seto S. (1973) ${ }^{13} \mathrm{C}$ nuclear magnetic resonance spectra of glucobiose, glucotriose, and glucans. J Chem Soc Perkin Trans. I.; 1: 2425-32.

Vincent M. (1970) A Manual for the practical study of root-nodule bacteria. International biological programme, handbook no. 15 Blackwell, Oxford, Edinburgh.

York WS, McNeil M, Darvill AG, Albersheim P. (1980) Beta-2-linked glucans secreted by fast-growing species of Rhizobium. $J$ Bacteriol.; 142: 243-8.

York WS, Darvill AG, McNeil M, Stevenson TT, Albersheim P. (1986) Isolation and characterisation of plant cell walls and cell wall components. Methods Enzymol.; 118: 3-40. 